\title{
Productivity Analysis on Local Government-owned Drinking Water Companies (PDAMs) in Indonesia and Its Market Challenge
}

\author{
Anang Mufftiadi \\ Business Administration Study Program \\ Faculty of Social and Political Sciences, Universitas Padjadjaran \\ Bandung, Indonesia \\ anang.muftiadi@unpad.ac.id
}

\begin{abstract}
Potential market for Local Government-owned Drinking Water Companies (PDAMs) in Indonesia are huge, but the performances are unsatisfactory. In 2014 , only $51 \%$ classified as 'healthy'. The aim of this study is to identify production characteristics using Cobb Douglas Model, which is the functional relationship between output (production quantities) with input (amount of human resources and assets). Quantity production is the basis to enhanced customer service and realization of the potential market. The data used is as much as 358 PDAMs in Indonesia. The result showed that there is highly significant inluence of the number of human resources and assets on the production quantity, with coefficient of determination of 0.75. Elasticity of production of assets $=0.277$ and of human resources $=0.91$. Furthermore $($ alpha + beta $)=1.19$, which showed that the production function is increasing returns to scale. Refer to this model, as many as $186(52 \%)$ classified as productive and $172(\mathbf{4 8 \%})$ classified as unproductive. The productive PDAMs, basically have better market opportunities exploitation and potentially attract investors. PDAMs in Indonesia do not have reliable level of production to increase its market coverage yet, because of their low scale of production.
\end{abstract}

Keywords-Cobb-Douglass, Increasing Return to Scale

\section{INTRODUCTION}

The drinking water is one of the basic needs for human life. Drinking water is water used for domestic purposes, drinking, cooking and personal hygiene. Because of the important functions, then the water become important concern internationally (MDGs and SDGs targets). The countries targeted achievement of the population access to drinking water for life support a certain level of prosperity and growth. Indonesia also set a target of achieving access to drinking water for the entire population (water for all) in 2019. Until 2015, the realization of access to drinking water Indonesia reached $71 \%$ which is provided by the government, households, private sectors, and communities. PDAMs that produce pipeline system of drinking water supply, cover $17 \%$ of households in Indonesia and are generally located in urban areas. More than $54 \%$ access to safe drinking water is obtained from wells, springs and rain water. As many as $29 \%$ of households can't access safe drinking water [1]. In this situation, basically PDAMs have huge market opportunity by providing services to households who have not access to safe drinking water and the others who want to change from non-piped system into the pipeline system, due to health and environmental safety.

However, general performance of those PDAMs seem do not able to answer the challenge. Refer to PDAMs Performance Report from Ministry of Public Works and Public Housing year 2014, as many as $20 \%$ (72) classified as 'sick', $27 \%$ (100) classified as 'less-healthy' and, 53\% (196) 'healthy'. The number of customers significantly contribute to determine the healthy rate of PDAMs [2]. There are PDAMs that actually have the ability to achieve better health levels, as many as 174 $(52.1 \%)$. However, $70 \%$ of them have not been able to realize this potential. Furthermore, minimum number of customers of PDAMs that support their 'healthy rate' is approximately 19,800 customers. The more customers, the hihger healthy rate of company will be. On the contrary, PDAMs with smaller number of customers will face greater barriers to grow. Number of customers itself are depended on the quantity of dringking water production [3].

Refer to above situation, this paper will be focused on the problem of drinking water production of PDAMs in Indonesia, especially on its productivity. The aim is to determine PDAMs productivity level as well as categorization of individual productivity. These will become important information for production strategies on PDAMs and policy-making, including local government policy to improve the performance of water enterprises and take opportunities of huge market size.

\section{RESEARCH PROBLEMS}

PDAMs are almost characterize as monopolistic companies, but unfortunately they are difficult to take advantage of huge market opportunities. Hypotetically, the fundamental cause is on their productive capacity. In this circumstances, analyzing productivity will be very important, primarily in efforts to (1) analyze and categorize the productivity level (2) identify policies and strategies on PDAM drinking water production 


\section{THEORETICAL BACKGROUND}

\section{A. Theory of Production}

Goods/ services production activity is an important aspect in business. Production is essentially as a core function of the business. In general, the production can be described as the process of transforming inputs into outputs (products) in a certain way. Production is the process of using materials and factor services, in conjunction with technology, to create new goods and services [4]. In the other reference, production in economics can be thought of as any activity which alters the form of materials, their quality and their availability over space and time. It can be thought of as a process of transformation of goods and services into different goods and services [5].

\section{B. Production Function}

Production requires factors of production such as labor, machinery, land, raw materials, organization and business ideas. The company strives to combine the various inputs to achieve efficient as possible combination of inputs to produce an output. It's stated that [4]:

Production uses inputs such as labour, machinery, buildings, land, raw materials, energy, ideas and organisation. These are commonly refered to as the factors of production. A firm combines these inputs through a technique or method of production to produce an output. The firm also attempts to combine these inputs as efficiently as possible.

Production on a business activity, can be studied through the form of the production function. This production function can be used as the basis for the decision inputs to generate a specific output. This production function is also used as an estimatation. Characteristics of the production function described as follow [4].

The input-output relationship is described by a conceptual tool called a production function. The neoclassical theory of production, and by association the neoclassical theory of the firm, is often called a black box theory. This is because it provides no details about 'soft' or qualitative issues that are internal to the firm, such as how the firm is structured and the nature of its culture.

Refer to another reference, function of production as [5]:

A production function can therefore be defined as a technical specification of the relationship between inputs and outputs in a particular production process. In its general form the production function simply identifies the possible outputs for given inputs.

The production function is also very important to analyze the productivity of a production process. In general, the production function can be expressed in the following model [5].

$\mathrm{Q}=\mathrm{f}(\mathrm{F} 1, \mathrm{~F} 2, \mathrm{~F} 3, \mathrm{~F} 4$..........Fn $)$ where;

$\mathrm{Q}=$ Quantity of production

$\mathrm{F} 1=$ Factor of production 1

$\mathrm{Fn}=$ Factor of production 2

Thus the production function gives an explanation of the correlation between the input to the output through a process that is not described in the function or so-called black box. Nevertheless, this production function can still benefit by purpose.

Basic production functions in the above equation, in practice can be developed to a variety of models, including famous model of Cobb Douglass.

\section{Cobb-Douglass Model}

Cobb-Douglass production function model which is best known in economics, as is in the following equation [5]:

$$
\mathrm{Q}=\mathrm{A} K^{\alpha} \mathrm{L}^{\beta}
$$

$\mathrm{Q}$ refers to the level of output, A is a constant which takes different values for different firms, using different technologies and located in different parts of the world. $\alpha$ and $\beta$ are also constant and signify the contribution both labour $(\mathrm{L})$ and capital $(\mathrm{K})$ make to different levels of output. These are referred to as elasticity coefficients. On the basis of past production data, economists work out the values for $A, \alpha$ and $\beta$ and the firm can then calculate its output for combinations of inputs. Q referred to the output, and $\mathrm{L}$ and $\mathrm{K}$ were the labour and capital inputs.

Based on those elasticity coefficient, it can then be interpreted, if:

- $\alpha+\beta=1$ then the production function is called constant returns to scale.

- $\alpha+\beta<1$ then the production function is called decreasing returns to scale.

- $\alpha+\beta>1$ then the production function is called increasing returns to scale.

Situation of increasing returns to scale are usually relatively favored by business, because with each increase in input of $1 \%$, can lead to an increase in output of more than $1 \%$.

\section{METHOD}

\section{A. Research Variables}

This researh uses a Cobb Douglass Production Function Model, in the following equation;

$$
\mathrm{Q}=A K^{\alpha} L^{\beta}+\mathrm{e}
$$




$$
\ln \mathrm{Q}=\mathrm{A}+\alpha \cdot \ln \mathrm{K}+\beta \cdot \ln \mathrm{L}+\mathrm{e}
$$

where:

$\mathrm{Q}=$ quantity of PDAMs drinking water production (liters per second)

$\mathrm{A}=$ constant (coefficient technology)

$\mathrm{K}=$ value of PDAMs assets $(\mathrm{Rp})$

$\mathrm{L}=$ number of PDAMs of human resources (people)

$\alpha=$ coefficient of productivity of capital

$\beta=$ coefficient of productivity of human resources

\section{B. Data Collection}

The data used in this research are secondary source from Ministry of Public Works and Public Housing of Republic Indonesia in Jakarta. The data published in PDAMs Performance Book Year 2014-2015 of four regions in Indonesia. Those data then compiled into structured data, especially on the above variables/ indicators.

\section{Research Design}

- To prepare data required of equation 2. Selected data variables are from Ministry of Public Works and Public Housing of all PDAMs in Indonesia. The raw data are transformed into natural $\log (\ln )$, to be processed into a linear regression.

- To calculate the Cobb-Douglas function and testing. Calculating Cobb Douglass production function model with econometric methods and needed test of t-test and F-test.

- To interpret the general productivity levels of PDAM in Indonesia. Knowing the level of general productivity PDAMs in Indonesia, if $\alpha+\beta>1$ than categorized into productive PDAMs (increasing returns to scale), and if $\alpha+\beta=1$ is as unitary (constant returns to scale), and if $\alpha+\beta<1$ is as unproductive (decreasing return to scale).

- To categorize productivity level of PDAMs. Based on equations no.4, then calculate ratio of estimated quantity of Q or Qest by entering the actual value of $\mathrm{K}$ and L. Ratio between Qest by actual quantity of production (Qact), indiciate that, if Qest / Qact> 1, then classified into unproductive PDAMs. If Qest / Qact = 1, then classified as normal and if Qest / Qact <1, classified as productive PDAMs.

- Identify policies and strategies on PDAMs drinking water production, based on the above categories.

\section{RESULTS AND DISCUSSION}

\section{A. Level of Production}

The different level of production among PDAMs in Indonesia is very high. PDAM of Jakarta is the highest production level (excluded as outliers) and the 358 PDAMs relatively small. Approximately $93.6 \%$ of PDAM, their production quantity of drinking water is less than 913 liters per second. Around 39.5\% (133 PDAMs), their quantity of production is even less than 94 liters per second. The general information of the quantity of production, can be seen in the figure below. Right side figure, shows further detail of PDAMS with low quantity of production.
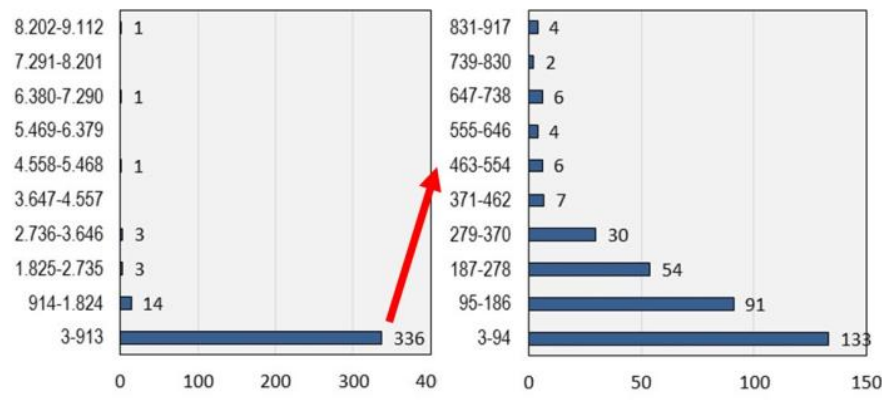

Fig. 1. Classification of PDAMs Quantity of Production Year 2014 (liters per second)

TABLE I. PDAMs Profile

\begin{tabular}{|l|l|l|l|l|}
\hline & $\begin{array}{c}\text { Production } \\
\text { (liter per } \\
\text { second) }\end{array}$ & $\begin{array}{c}\text { Asset } \\
\text { (Rp.Billion) }\end{array}$ & $\begin{array}{c}\text { Human } \\
\text { Resources } \\
\text { (person) }\end{array}$ & $\begin{array}{c}\text { Water } \\
\text { Losses } \\
\text { Level } \\
(\%)\end{array}$ \\
\hline Average & 307 & 54 & 145 & 33,2 \\
\hline $\begin{array}{l}\text { Variation } \\
\text { Coefficient }\end{array}$ & $242 \%$ & $207 \%$ & $152 \%$ & $38,4 \%$ \\
\hline
\end{tabular}

Average quantity of drinking water production of 358 PDAMs is 307 liters per second. Average value of its assets amounted to Rp.54 billion and the number of human resources as much as 145 . Within their production process, average water loss (non-revenue water) is relatively high, at $33.2 \%$ of the entire production. Those four PDAMs indicator show that difference in production level is the biggest than followed by value of assets, human resources and level of water losses.

\section{B. Production Function Analysis}

Data processing of 358 PDAMs with the regression equation for the Cobb-Douglas model shows that assets and human resources are highly significant influence on the quantity of drinking water production. Likewise, simultaneous testing is also very significant. The coefficient of determination is strong, which is 0.75 . The equations transformation into the Cobb-Douglas production function, is as follow,

$$
\ln \mathrm{Q}=\underset{(-8,36)^{* *}}{-3,96}+\underset{(7,70)^{* *}}{0,277 \ln \mathrm{K}}+\underset{(17,25)^{* *}}{0,908 \ln \mathrm{L}}
$$

$\mathrm{F}=545,18^{*}$

$\mathrm{R}^{2}$ adj $=0,75$

$$
\mathrm{Q}=-3,96 \cdot \mathrm{K}^{0,277} \mathrm{~L}^{0,908}
$$


Cobb Douglas coefficients are alpha $=0,277$ and beta $=0,908$. Summation of coefficients, $0.277+0.908=1.185$, indicate that the drinking water production function shows the situation of increasing returns to scale. This means that if there are additional input (assets and human resources) of the fold, then the quantity of production will increase 1,185-fold. These condition basically shows that drinking water production are likely to have a positive character to increase production capacity effectively. Quantity of production could be the key to huge market size realization.

\section{Productivity Level}

Based on the equation (6), individual assessement on level of PDAMs productivity held by arranging ratio between estimated quantity of production to actual quantity production. As many as 186 PDAMs (52\%) have ratio value more than 1 or classified as productive PDAMs. As many as 172 PDAMs $(48 \%)$ have ratio value smaller than 1 or relatively less productive. This classification shows that PDAMs in Indonesia are facing fundamental problem to cover the market.

Furthermore, if the productivity ratio was correlated with the quantity of production, it seems that there is a positive relationship between the two. It means that level of productivities are generally caused by its level of production quantity. This indicates that generally, PDAMs in Indonesia do not have a reliable level of productivity to be able to increase its market coverage.

Opportunity for productive PDAMs in order to increase their quantity of production through new invesment is higher. Increasing production in an productive company will enhance efficiency. This will result not only PDAMs performance, but also in wider service of coverage. This coincides with following [6];

Increase of investments in the network, the institutionallegal form of the company and the number of connections per $\mathrm{km}$ of network appear to be the most important characteristics of the differences in the actual efficiency of water supply per connection.

Scale of production problem thus becomes a basic and strategic issues for PDAMs performance improvement [7]. As long as this fundamental problems can not be solved properly, hence solving other problems it is only for a short period impact. The next big challenge faced in improving drinking water production is the availability of water source, which are relatively difficult or complex provisioning [8].

TABLE II. LEVEL OF PDAMS PRODUCTIVITY CLASSIFICATION

\begin{tabular}{|l|c|c|}
\hline \multicolumn{1}{|c|}{ Category } & $\begin{array}{c}\text { Number of } \\
\text { PDAM }\end{array}$ & \% \\
\hline Productive & 186 & 52,0 \\
\hline Less Productive & 172 & 48,0 \\
\hline Total & $\mathbf{3 5 8}$ & $\mathbf{1 0 0}$ \\
\hline
\end{tabular}

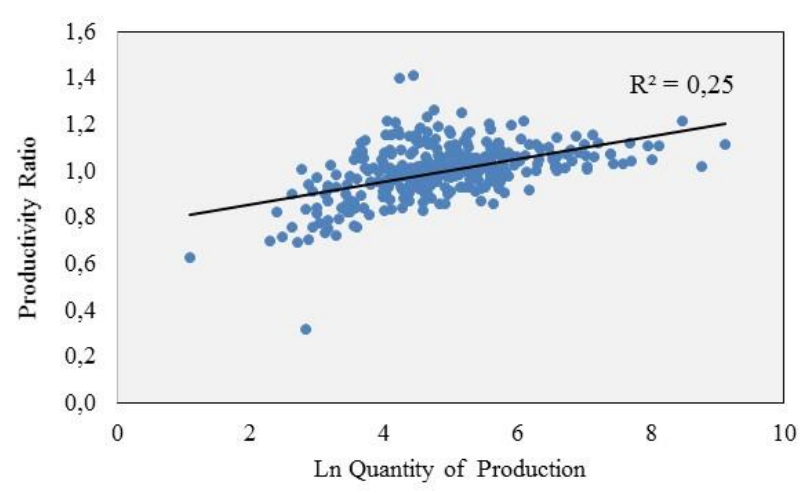

Fig. 2. Productivity and Production Quantity Correlation of PDAMs

\section{CONCLUSION AND RECOMMENDATION}

\section{A. Conclusion}

This research showed that there is highly significant inluence of the number of human resources and assets on the production quantity, with coefficient of determination of 0.75 . Elasticity of production of assets (alpha) $=0.277$ and elasticity of human resources $($ beta $)=0.91$. Furthermore $($ alpha + beta $)=$ 1.19, which showed that the PDAMs production is characterized by increasing returns to scale, that is, if there are additional input $1 \%$, then the output will increase by more than $1 \%$. Refer to this model, as many as $186(52 \%)$ classified as productive and $172(48 \%)$ classified as unproductive. The productive PDAMs, basically have better market opportunities exploitation. In order to exploite market opportunities, in view of production side, the productive PDAMs can potentially attract investors. Nevertheless, other non-technical issues still need to be considered, such as water prices, water losses, etc. In general, PDAMs in Indonesia do not have reliable level of productivity to increase its market coverage, because of their low scale of production. As long as this fundamental problem can not be solved properly, hence solving the other problems are only have short term impact.

\section{B. Recommendation}

- The less productive PDAMs in Indonesia need to utilize its asset and human resources in order to achieve efficiency. Productive PDAMs need to increase services coverage or its market expansion.

- Government support on source water provision as a fundamental step to increase scale of production of PDAMs are urgently required. Availability of source of water will ensure sustainability and development of PDAMs 


\section{REFERENCES}

[1] Statistics Indonesia, "National Survey on Social and Economy (Susenas)", 2014

[2] Muftiadi, Anang and Herawati, Tetty, "Analysis of production efficiency based on quantity of production and types of source water on Local Government Owned Water Supply Companies (PDAMs) in Indonesia," FISIP Universitas Padjadjaran, 2013 (unpublished).

[3] Muftiadi, Anang, "Benchmark analysis on production cost on Local Government Owned Water Supply Companies (PDAMs) in Indonesia (cost curve model)," Presented in XIII ${ }^{\text {th }}$ Cultural Simposium of Indonesia Malaysia, Bandung, Indonesia, 2013

[4] Earl, Peter and Wakeley, Tim, "Business economics: A contemporary approach," McGraw-Hill Education, Berkshire, UK, 2005,p37-177.

[5] Lipczynski, John and Wilson, John, "The economics of business strategy," Prentice Hall, Pearson Education Limited, UK, 2004,p35-64.
[6] Dalhuisen, Jasper M., Nijkamp, Peter, "Regulatory impacts on sustainable drinking water supply: a comparative study on Dutch water companies", International Journal of Environmental Technology and Management, 2006 Vol.6,No.6 pp.564-582.

[7] Muftiadi, Anang, "Relationship and critical limits on scale and healthy rate of Local Government Owned Water Supply Companies (PDAMs) in Indonesia, "Proceeding of International Conference of Inter Studies, Young San University, South Korea, 2014

[8] Listyawan, Budi and Muftiadi, Anang., et.al, "On paving the right way in drinking water Services : Strung in success story of PDAMs executives," Indonesia Ministry of Public Works Publishing, 2013,p73-177. 